\title{
The anti-neoplastic activity of Vandetanib against high-risk medulloblastoma variants is profoundly enhanced by additional PI3K inhibition
}

\author{
Rogerio B. Craveiro ${ }^{1, *}$, Michael Ehrhardt ${ }^{1,}{ }^{*}, J^{\prime} u l i a$ Velz $^{1}$, Martin Olschewski ${ }^{1}$, Barbara \\ Goetz $^{1}$, Torsten Pietsch ${ }^{2}$ and Dagmar Dilloo ${ }^{1}$ \\ ${ }^{1}$ Department of Pediatric Hematology and Oncology, Center for Pediatrics, University of Bonn Medical Center, D-53113 Bonn, \\ Germany \\ ${ }^{2}$ Department of Neuropathology, University of Bonn, D-53105 Bonn, Germany \\ *These authors have contributed equally to this work \\ Correspondence to: Rogerio B. Craveiro, email: Rogerio.craveiro@ukb.uni-bonn.de \\ Keywords: medulloblastoma, Vandetanib, GDC-0941, targeted therapy, multi-kinase inhibitor (MKI) \\ Received: July 27, $2016 \quad$ Accepted: December 26, $2016 \quad$ Published: January 31, 2017 \\ Copyright: Craveiro et al. This is an open-access article distributed under the terms of the Creative Commons Attribution License \\ 3.0 (CC BY 3.0), which permits unrestricted use, distribution, and reproduction in any medium, provided the original author and \\ source are credited.
}

\section{ABSTRACT}

Medulloblastoma is comprised of at least four molecular subgroups with distinct clinical outcome (WHO classification 2016). SHH-TP53-mutated as well as MYCamplified Non-WNT/Non-SHH medulloblastoma show the worst prognosis.

Here we present evidence that single application of the multi-kinase inhibitor Vandetanib displays anti-neoplastic efficacy against cell lines derived from high-risk SHH-TP53-mutated and MYC-amplified Non-WNT/Non-SHH medulloblastoma. The narrow target spectrum of Vandetanib along with a favourable toxicity profile renders this drug ideal for multimodal treatment approaches. In this context our investigation documents that Vandetanib in combination with the clinically available PI3K inhibitor GDC-0941 leads to enhanced cytotoxicity against MYC-amplified and SHH-TP53-mutated medulloblastoma. In line with these findings we show for MYC-amplified medulloblastoma a profound reduction in activity of the oncogenes STAT3 and AKT. Furthermore, we document that Vandetanib and the standard chemotherapeutic Etoposide display additive anti-neoplastic efficacy in the investigated medulloblastoma cell lines that could be further enhanced by PI3K inhibition. Of note, the combination of Vandetanib, GDC-0941 and Etoposide results in MYC-amplified and SHH-TP53-mutated cell lines in complete loss of cell viability. Our findings therefore provide a rational to further evaluate Vandetanib in combination with PI3K inhibitors as well as standard chemotherapeutics in vivo for the treatment of most aggressive medulloblastoma variants.

\section{INTRODUCTION}

Angiogenesis is critical for tumor growth and metastasis, therefore receptor tyrosine kinase inhibitors targeting tumor blood vessel formation by VEGFR inhibition increasingly gain access to multimodal therapeutic approaches against brain tumors [1,2]. Recent clinical studies in adult and pediatric patients suffering from glioblastoma multiforme and diffuse pontine glioma document anti-neoplastic activity within the central nervous system and good tolerability of Vandetanib in single use or in combination with radio- and chemotherapy [3-5]. Against this background our study evaluates the potency of Vandetanib for medulloblastoma treatment, the most common malignant brain tumor of childhood. Numerous molecular studies document that medulloblastoma is not one disease but composed of molecular distinct subgroups [6]. Overall survival for patients suffering from SHHTP53 mutated and MYC-amplified Non-WNT/Non-SHH medulloblastoma subtypes is poor with the highest risk of recurrence and death within this patient cohort $[7,8]$ 
The efficacy of Vandetanib has been suggested to rely not solely on inhibition of angiogenesis but also on direct attenuation of tumor growth by blockade of its target receptors namely vascular, endothelial growth factor receptor 2 and 3, epidermal growth factor receptor (EGFR) and c-RET expressed on the cancer cells themselves. [9-11]. VEGFR-2 and EGFR receptors have recently been identified as medulloblastoma oncogenes with EGFR gene amplification and overexpression being a marker of poor prognosis [12-16]. We hypothesize that the most aggressively growing medulloblastoma variants characterized by dependency on tumor-angiogenesis and expression of receptor tyrosine kinases represent an attractive target for Vandetanib therapy. However, despite the successful incorporation of Vandetanib into treatment regimes for adult malignancies, assessment of efficacy in pediatric tumor entities is sparse with no preclinical or clinical studies analyzing its use for medulloblastoma treatment yet $[17,18]$.

Here we present first evidence that Vandetanib has profound cytotoxic activity in pediatric medulloblastoma cell lines derived from high-risk SHH-TP53-mutated and MYC-amplified Non-WNT/Non-SHH medulloblastoma [19-25]. In keeping with the observed anti-neoplastic capacity we demonstrate that Vandetanib treatment attenuates AKT and STAT3 activity, downstream elements of aberrant signaling pathways in medulloblastoma [26-30].

In our latest study we already documented promising in vitro and in vivo potential for the clinically available PI3K inhibitor GDC-0941 for medulloblastoma therapy [31]. In this follow-up study we show that specifically inhibiting oncogenic receptor tyrosine kinases in combination with downstream elements such as PI3K on which multiple carcinogenic pathways converge might be a rational treatment strategy for aggressive medulloblastoma variants. In this context we observed that the concomitant application of Vandetanib and GDC-0941 resulted in augmented cytotoxicity for MYC-amplified and SHH-TP53-mutated medulloblastoma. In MYC-amplified medulloblastoma we also detected a corresponding reduction of AKT and STAT3 phosphorylation and protein levels compared to single drug treatment. Furthermore, we document that concomitant application of Vandetanib and the standard chemotherapeutic Etoposide leads to enhanced cytotoxicity in comparison to single drug application. Additional inhibition of the PI3K by GDC-0941 further augmented this marked antineoplastic efficacy of the Vandetanib-Etoposide combination with de facto no surviving cells in MYC-amplified and SHH-TP53-mutated medulloblastoma. Thus, therapeutic approaches based on inhibition of oncogenic kinases alone or in combination with standard chemotherapeutics might constitute a promising treatment option for medulloblastoma variants with poor clinical outcome to date.

\section{RESULTS}

\section{In medulloblastoma Vandetanib reduces cell viability in a dose-dependent manner}

In a dose-response analysis we evaluated the anticarcinogenic potency of Vandetanib in Daoy, a cell line modeling SHH-TP53-mutated medulloblastoma, and in the MYC-amplified Non-WNT/Non-SHH medulloblastoma derived cell lines MEB-Med8-A, D283 Med and D341

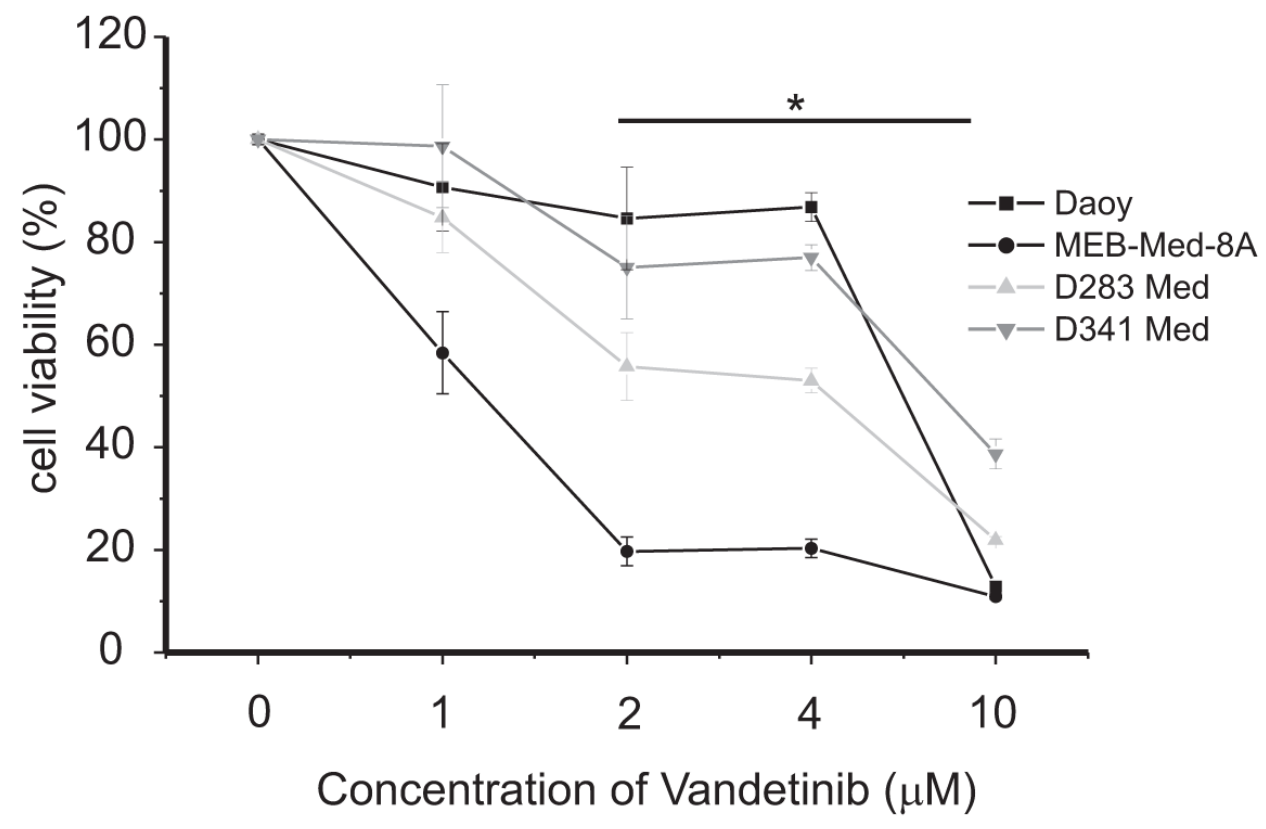

Figure 1: Vandetanib treatment leads to a dose-dependent reduction of medulloblastoma cell viability. The cell lines MEB-Med-8A, D283 Med, Daoy and D341 Med were treated with increasing concentrations of vandetanib. The vehicle DMSO served as control. After $48 \mathrm{~h}$ of drug exposure the cell viability was assessed by means of the MTS assay. Statistically significant differences from DMSO are marked by an asterisk $(* \mathrm{p}<0.05)$, the data shown represent four independent experiments. 
Med, (Figure 1). At standard growth conditions the cells were treated with Vandetanib concentrations ranging from 1 to $10 \mu \mathrm{M}$ for $48 \mathrm{~h}$. Subsequently the cell viability was determined by MTS assays.

At $2 \mu \mathrm{M}$, a concentration corresponding to patient plasma levels $[5,32]$, Vandetanib reduced cell viability in Daoy by $15 \pm 9 \%$, in MEB-Med- 8 A by $81 \pm 3 \%$, in D283 Med by $44 \pm 6 \%$ and in D341 Med by $25 \pm 9 \%$ in comparison to control. With regards to Vandetanib susceptibility, MEBMed-8A and D283 Med were of high responsiveness while Daoy and D341 displayed lower sensitivity. A further decline in cell viability could only be achieved when raising the drug concentration to $10 \mu \mathrm{M}$. At this concentration we observed a profound loss in cell viability across all analysed cell lines with a minimum residual cell survival of $10-40 \%$.

\section{Vandetanib reduces viable cell number and exerts anti-proliferative and pro-apoptotic effects in medulloblastoma cell lines}

After $48 \mathrm{~h}$ of Vandetanib treatment we determined the absolute number of viable cells by flow cytometry and assessed the relative contribution of cell death and proliferation inhibition via combined CFSEHoechst33258 stain.

Exposing the cell lines to $2 \mu \mathrm{M}$ of Vandetanib over $48 \mathrm{~h}$ significantly decreased the absolute number of viable cells in Daoy by $35 \pm 16 \%$, in MEB-Med- 8 A by $67 \pm 6 \%$, in D283 Med by $41 \pm 11 \%$ and in D341 Med by $27 \pm 9 \%$ (Figure 2A). The CFSE-Hoechst33258 stain revealed that this profound loss in absolute cell numbers over a $48 \mathrm{~h}$ period was predominantly due to the cytotoxic activity of Vandetanib and complemented by a less pronounced antiproliferative effect (Figure 2B and 2C). At 48h, in Daoy, MEB-Med-8A and D341, $13 \pm 2 \%, 24 \pm 4 \%$ and $4 \pm 1 \%$ of dead cells were determined respectively. In D283 Med cell death differed not significantly from control at the assessed time point. With regards to proliferation in MEB-Med-8A a marked reduction of proliferating cells by $21.5 \%$ was observed at the $48 \mathrm{~h}$ time point In contrast in Daoy, D283 Med and D341 Med proliferation in cells surviving after $48 \mathrm{~h}$ of Vandtanib exposure was only marginally impaired.

\section{Vandetanib interferes with the clonogenicity of medulloblastoma in a dose-dependent manner}

In view of their differential group affiliation, we chose Daoy and MEB-Med-8A to assess the efficacy of Vandetanib to interfere with medulloblastoma clonogenicity (Figure 3). Treatment of Daoy and MEBMed-8A with 1, 2 and $4 \mu \mathrm{M}$ of Vandetanib resulted in a dose-dependent reduction of colony numbers $(\mathrm{CN})$ and average colony size (ACS).
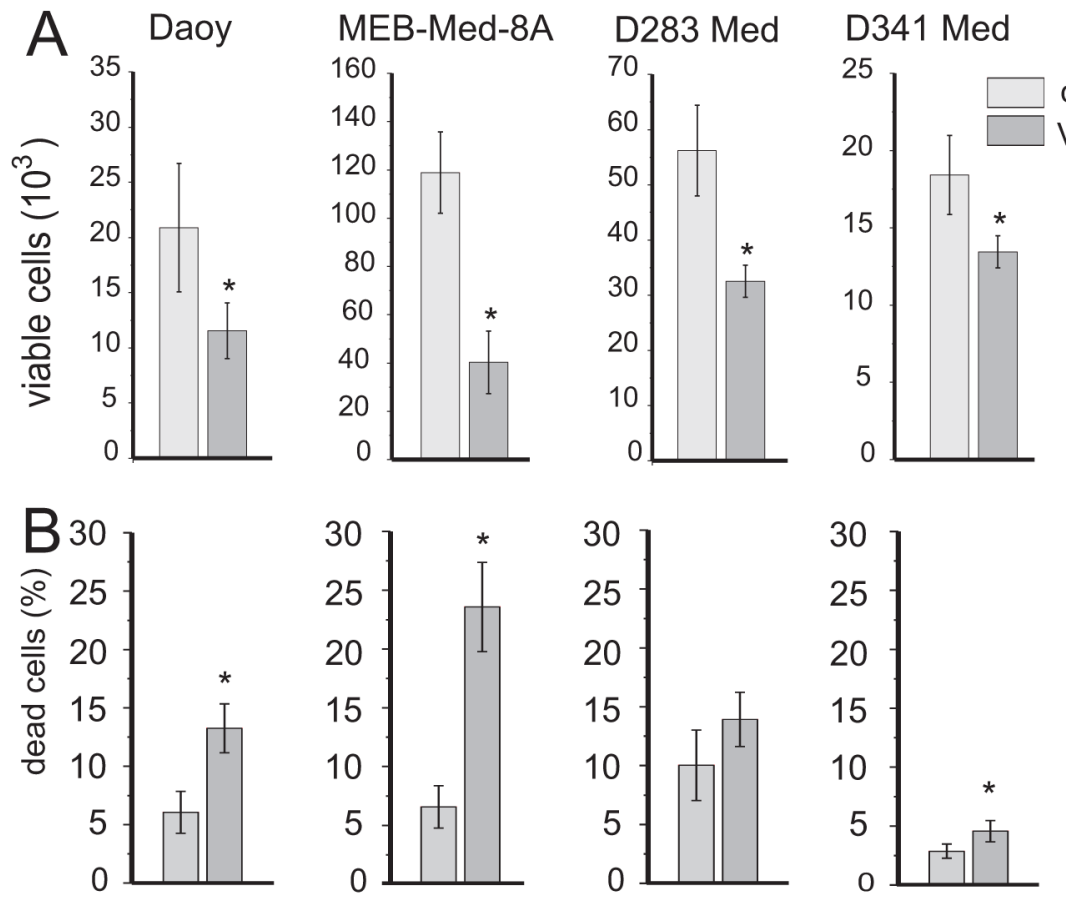

control

Vand. $2 \mu \mathrm{M}$

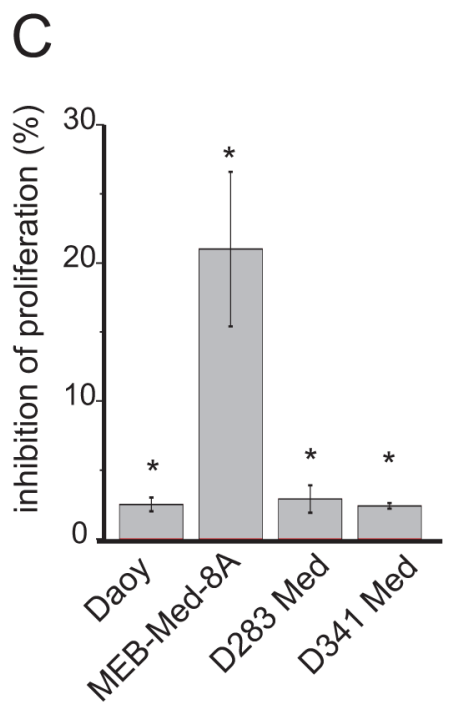

Figure 2: Vandetanib impairs cell viability in medulloblastoma. The established paediatric MB cell lines MEB-Med-8A, D283 Med, Daoy and D341 Med were treated with $2 \mu \mathrm{M}$ of Vandetanib for 48h. The vehicle DMSO served as the control. In a combined flow cytometric cell viability/proliferation assay based on a CFSE/Hoechst 33258 stain, viable cell number A. cell death B. and inhibition of proliferation C. was assessed. All statistically significant differences from DMSO are marked by an asterisk (*p<0.05) (A-C). Inhibition of proliferation was normalized to DMSO (C). The data shown represent four independent experiments. 
At $2 \mu \mathrm{M}$, a concentration typically achieved in patient plasma, MEB-Med-8A showed significant reduction of colony numbers and colony size $(\mathrm{CN}$ : $9 \pm 0.5$ and ACS: $\left.305 \pm 250 \mathrm{p}^{2}\right)$ in comparison to control $(\mathrm{CN}$ : $164 \pm 23$ and ACS: $1028 \pm 29 \mathrm{p}^{2}$ ). At the same concentration in Daoy we only documented a reduction in colony size $\left(1618 \pm 900 p^{2}\right)$ compared to control $\left(3723 \pm 1000 p^{2}\right)$ but not in colony numbers. Increasing the dose to $4 \mu \mathrm{M}$ enhanced the observed effects in both cell lines and additionally resulted for Daoy in a profound decline in the number of colonies $(173 \pm 45)$ in comparison to control $(300 \pm 35)$.

\section{Vandetanib attenuates medulloblastoma cell migration}

We also determined the potential of Vandetanib to inhibit medulloblastoma cell migration at different concentrations (Figure 4). The cell line Daoy was chosen because of its known migratory properties. [33]. After
24 hours at $2 \mu \mathrm{M}$, Vandetanib inhibited cell migration significantly $(215 \pm 45 \mu \mathrm{m})$ in comparison to control $(365 \pm 36 \mu \mathrm{m})$. Escalating the dose to $4 \mu \mathrm{M}$ did not lead to a further impairment of the migratory capacity of Daoy cells.

\section{Vandetanib and the PI3K inhibitor GDC-0941 display additive anti-neoplastic efficacy in medulloblastoma}

The PI3K/AKT pathway transduces signals of oncogenic receptor tyrosine kinases in medulloblastoma $[29,30]$. In this context we have previously shown in in vitro and in vivo medulloblastoma models that single application of GDC-0941 exerts profound anti-neoplastic activity [31]. We therefore asked whether additional blockade of the PI3K would enhance the cytotoxity of Vandetanib. Here we exposed medulloblastoma cell lines to $2 \mathrm{uM}$ of Vandetinib in combination with $1 \mathrm{uM}$
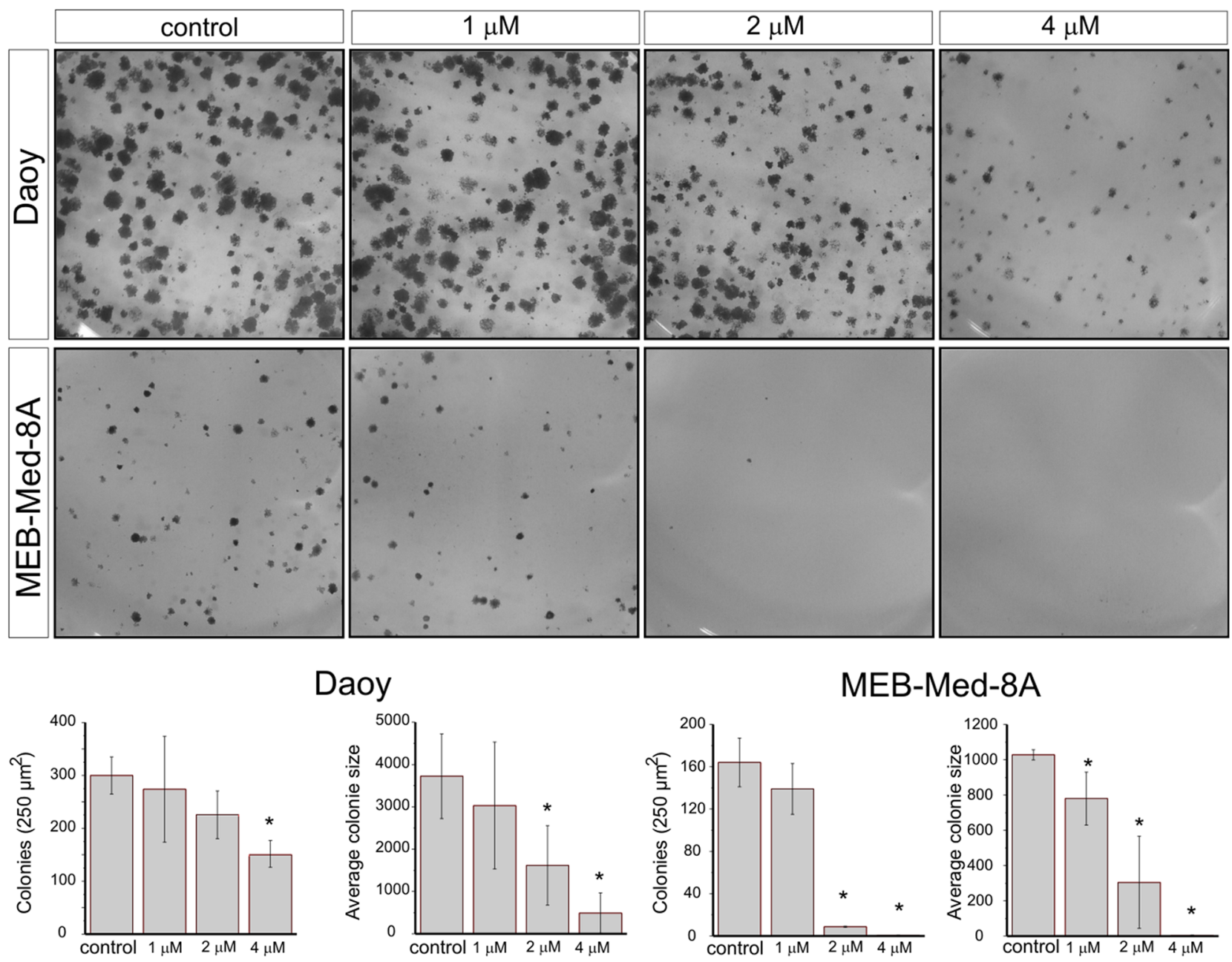

\section{Daoy}

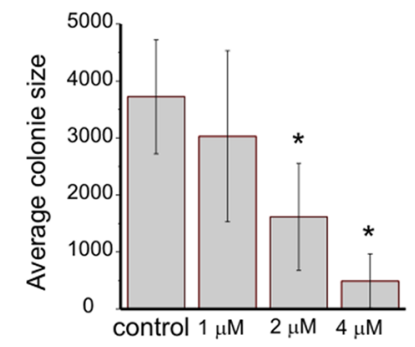

MEB-Med-8A

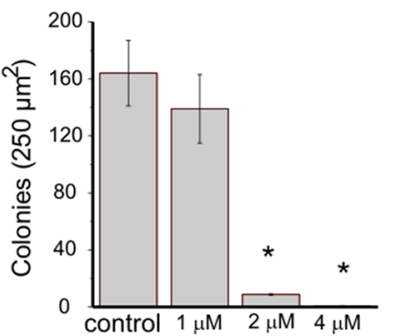

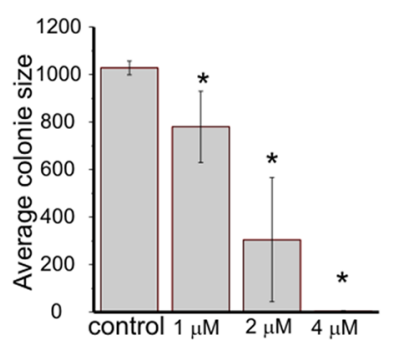

Figure 3: Vandetanib suppresses colony formation of medulloblastoma. Daoy and MEB-Med-8A cells were exposed to 1,2 and $4 \mu \mathrm{M}$ Vandetanib for $48 \mathrm{~h}$. Subsequently the cells were maintained in standard growth medium for 7 days and colony formation and colony size were assessed. Statistically significant differences from control are marked by an asterisk $(* \mathrm{p}<0.05)$. The data shown represent five independent experiments. 
of the P3IK-antagonist GDC-0941 for 48h. Both drug concentrations correspond to plasma levels found in treated patients $[32,34]$. Subsequently the number of viable cell was determined by flow cytometry. In order to differentially assess cell death in relation to proliferation, we applied a CSFE-Hoechst33258 stain (Figure 5).

In the MYC-amplified cell lines the combination of Vandetanib and GDC-0941 resulted in a significantly enhanced reduction of viable cells by $97 \pm 1 \%$ in MEBMed-8A, by $78 \pm 5 \%$ in D283 Med and by $62 \pm 1 \%$ in D341 Med in comparison to Vandetanib alone with $67 \pm 6 \%$, $41 \pm 11 \%$ and $27 \pm 9 \%$ and GDC-0941 alone with $81 \pm 2 \%$, $53 \pm 5 \%$ and $29 \pm 7 \%$ of residual viable cells in MEB-Med8A, D283 Med and D341 Med respectively. In the SHHTP53-mutated cell line Daoy we detected on average less residual cells for the drug combination in comparison to single drug application. However, this trend was not significant.

For the MYC-amplified cell lines MEB-Med-8A, D283 Med and D341 Med but not the SHH-TP53-mutated cell line Daoy concomitant exposure to Vandetanib and GDC-0941 led to significantly enhanced cytotoxicity compared to single drug treatment. At $48 \mathrm{~h}$ after drug treatment we document for the drug combination $84 \pm 5 \%$ of dead cells in MEB-Med-8A, $32 \pm 4 \%$ in D283 Med and $7 \pm 3 \%$ in D341 Med. In contrast Vandetanib single application resulted only in $24 \pm 4 \%$ of cell death in MEBMed-8A, $14 \pm 2 \%$ in D283 Med and $4 \pm 1 \%$ in D341 Med. In Daoy, D283 Med and D341 Med the effect of Vandetanib single application with $13 \pm 2 \%, 14 \pm 2 \%$ and $4 \pm 1 \%$ of dead cells was comparable to the application of GDC0941 alone with $9 \pm 4 \%, 14 \pm 5 \%$ and $3 \pm 1 \%$ of cell death respectively. In MEB-Med-8A with $40 \pm 3 \%$ cell death 1 $\mu \mathrm{M}$ GDC-0941 displayed more efficacy compared to 2 $\mu \mathrm{M}$ of Vandetanib with $24 \pm 4 \%$ cell death.

Only in MEB-Med-8A we determined a markedly enhanced inhibitory effect on proliferation with $39 \pm 4 \%$ when Vandetanib was combined with GDC-0941 in comparison to Vandetanib single treatment with $21 \pm 5 \%$ inhibition of proliferation. In Daoy, D283 Med and D341 Med proliferation was only marginally decreased by single application of Vandetanib or GDC-0941 at the assessed time point.

\section{Concomitant application of Vandetanib and GDC-0941 leads to profound reduction of AKT and STAT3 signaling in medulloblastoma cell lines}

Aberrant activation of the PI3K/AKT pathway and transcription factor STAT3 is considered critical for medulloblastoma carcinogenesis [26-31]. In keeping with these findings the four investigated medulloblastoma cell lines showed phosphorylation of serine 472 of AKT and tyrosine 705 of STAT3 (Figure 6).

Here we document that in Daoy Vandetanib treatment moderately decreased AKT phosphorylation and protein expression, while in MEB-Med-8A, D283 Med and D341 Med AKT signaling was unaffected by Vandetanib. With regards to STAT3 following treatment with Vandetanib a concomitant decrease in STAT3 phosphorylation and expression was apparent for Daoy and to a greater extent for MEB-Med8-A, but not D283 and D341.

Single treatment of GDC-0941 in Daoy, MEB-Med8A and D283 Med resulted in complete abrogation of AKT phosphorylation and a marked reduction in AKT protein levels, while in D341 Med residual AKT activity could be detected. STAT3 phosphorylation and protein expression was moderately decreased by GDC-0941 in Daoy, MEBMed-8A and D283 Med but not in D341 Med.

Application of the Vandetanib-GDC combination enhanced the reduction of AKT phosphorylation and expression only in D341 Med. In Daoy, MEB-Med-8A and D283 Med the already profound suppression of GDC0941 single application on AKT signaling was not further augmented by the drug combination. With respect to STAT3 activity however, the drug combination resulted in
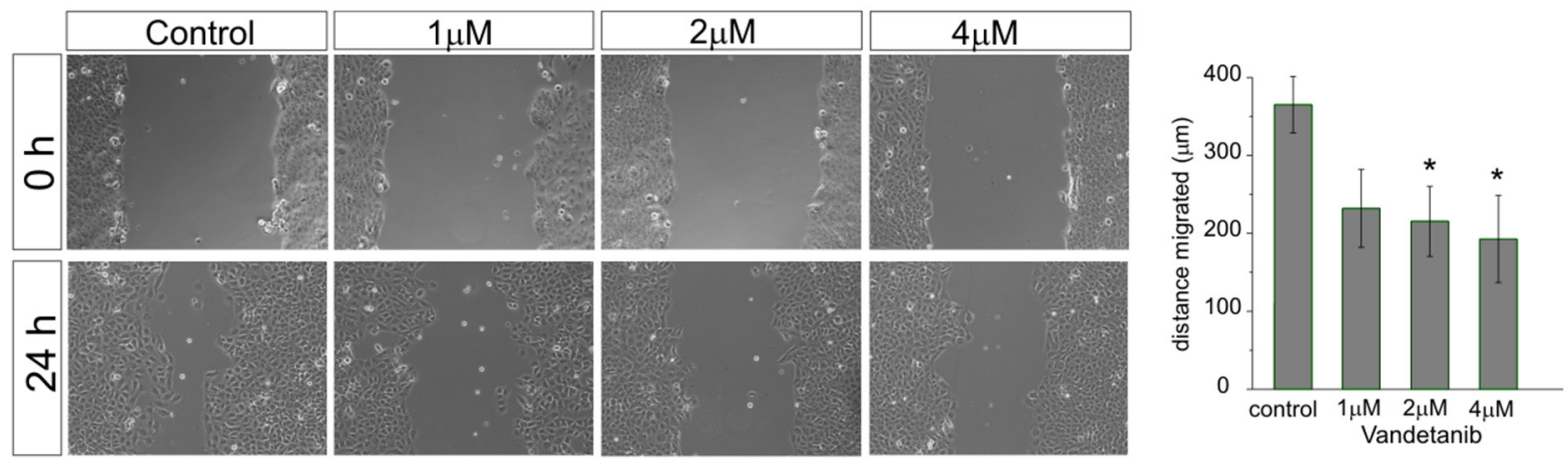

Figure 4: Vandetanib inhibits MB cell migration already at low concentrations. After a single scratch was placed in a confluent monolayer of Daoy cells, cell were exposed to increasing concentrations of Vandetanib for $24 \mathrm{~h}$. After $24 \mathrm{~h}$ each scratch was photographed and its width measured. Migration was determined by comparison of the scratch wound size between $0 \mathrm{~h}$ and $24 \mathrm{~h}$. Statistically significant differences from control are marked by an asterisk $\left({ }^{*} \mathrm{p}<0.05\right)$. The data shown represent five independent experiments. 
a more pronounced reduction of STAT3 phosphorylation and expression compared to single drug application in MEB-Med-8A, D283 Med and D341 Med. In Daoy in contrast, we could not observe any additional reduction in STAT3 phosphorylation or expression for the combination of Vandetanib and GDC-0941.

\section{Concomittant application of Vandetanib, GDC- 0941 and Etoposide displays additive cytotoxic activity in medulloblastoma}

The topoisomerase inhibitor Etoposide is part of the standard treatment regime for paediatric medulloblastoma. We analysed whether concomitant application of Vandetanib and Etoposide at concentrations corresponding to cerebral spinal fluid (1-2 $\mu \mathrm{M})$ or patient plasma $(10 \mu \mathrm{M})$ levels results in enhanced anti-neoplastic efficacy [35, 36]. For this purpose we treated medulloblastoma cell lines with Etoposide concentrations ranging from $0.1-10 \mu \mathrm{M}$ in combination with $2 \mu \mathrm{M}$ of Vandetanib for $48 \mathrm{~h}$ and determined the cell viability by MTS assay (Figure 7).

In the SHH-TP53-mutated cell line Daoy and the MYC-amplified cell lines D283 Med and D341 Med single application of Etoposide at cerebral spinal fluid levels of $1 \mu \mathrm{M}$ displayed anti-neoplastic efficacy with 30-60\% residual cell viability. In contrast MEB-Med-8A, which also models MYC-amplified tumors, was resistant at $1 \mu \mathrm{M}$ of Etoposide and displayed only moderate susceptibility to $10 \mu \mathrm{M}$ Etoposide corresponding to patient plasma levels with $74 \pm 4 \%$ residual cell viability.
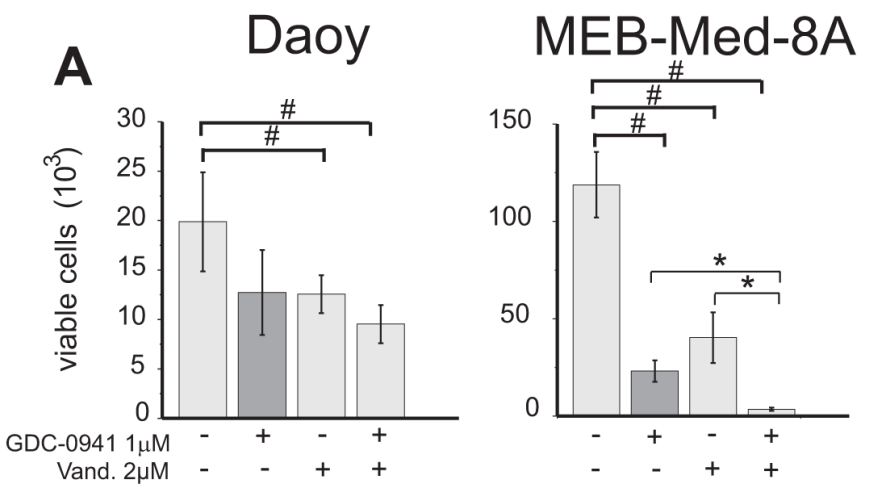

D283 Med

D341 Med
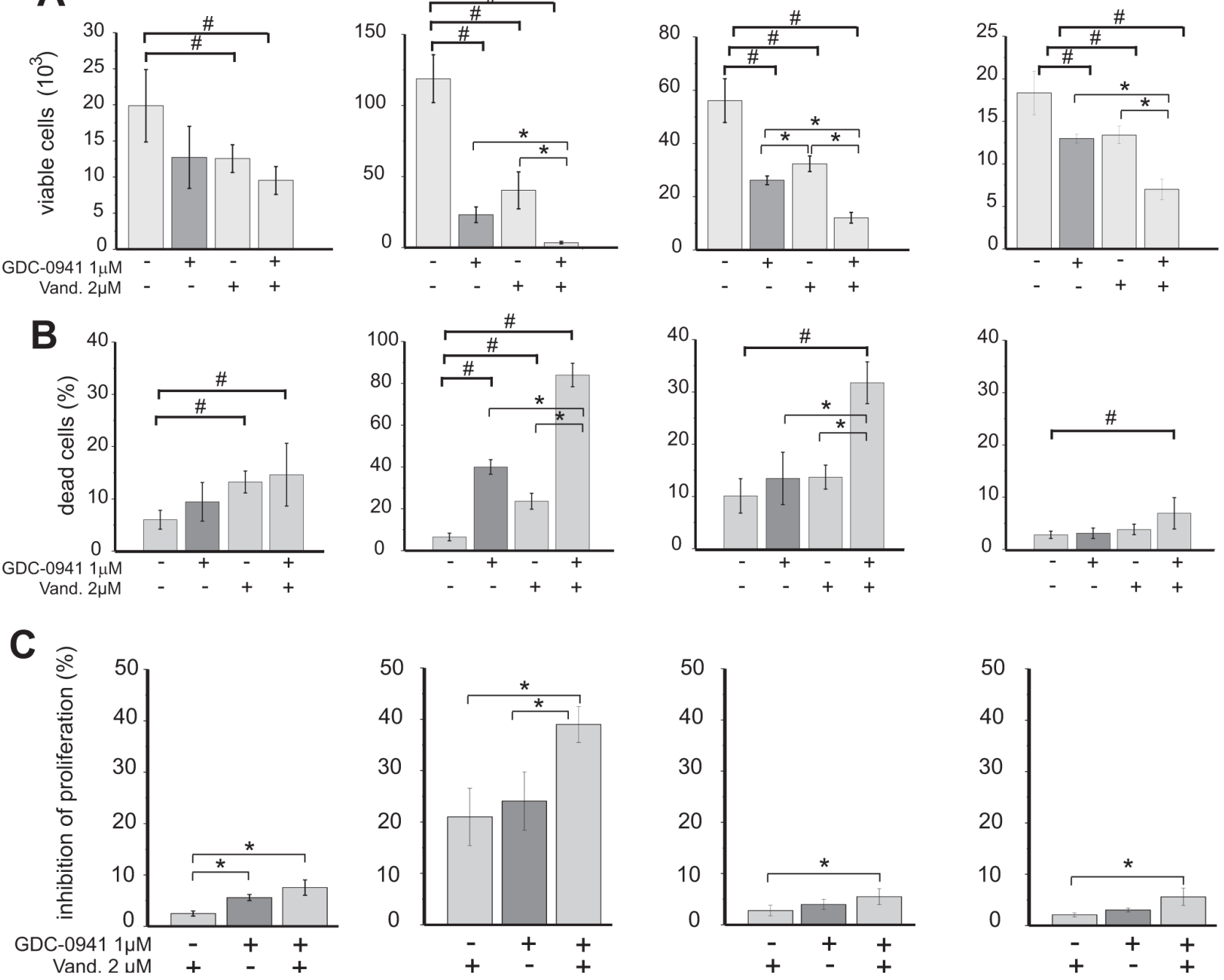

Figure 5: Determination of anti-proliferative and cytotoxic effects of Vandetanib in combination with the PI3K inhibitor GDC-0941. Medulloblastoma cells were treated with $2 \mu \mathrm{M}$ of Vandetanib or $1 \mu \mathrm{M}$ of the PI3K inhibitor GDC-0941 alone or in combination for $48 \mathrm{~h}$. Viable cell number A. cell death B. and inhibition of proliferation C. was analysed by flow cytometry following a CFSE/Hoechst 33258 stain. DMSO was used as control. Inhibition of proliferation was normalized to control DMSO and all stated values differ significantly $(\mathrm{p}<0.05)$ from the control DMSO. Other values tagged with a hashsign also differ significantly from the control $(\# \mathrm{p}<0.05)$, while all values tagged with an asterisk differ significantly from single drug application $\left({ }^{*} \mathrm{p}<0.05\right)$. The data shown represent four independent experiments. 


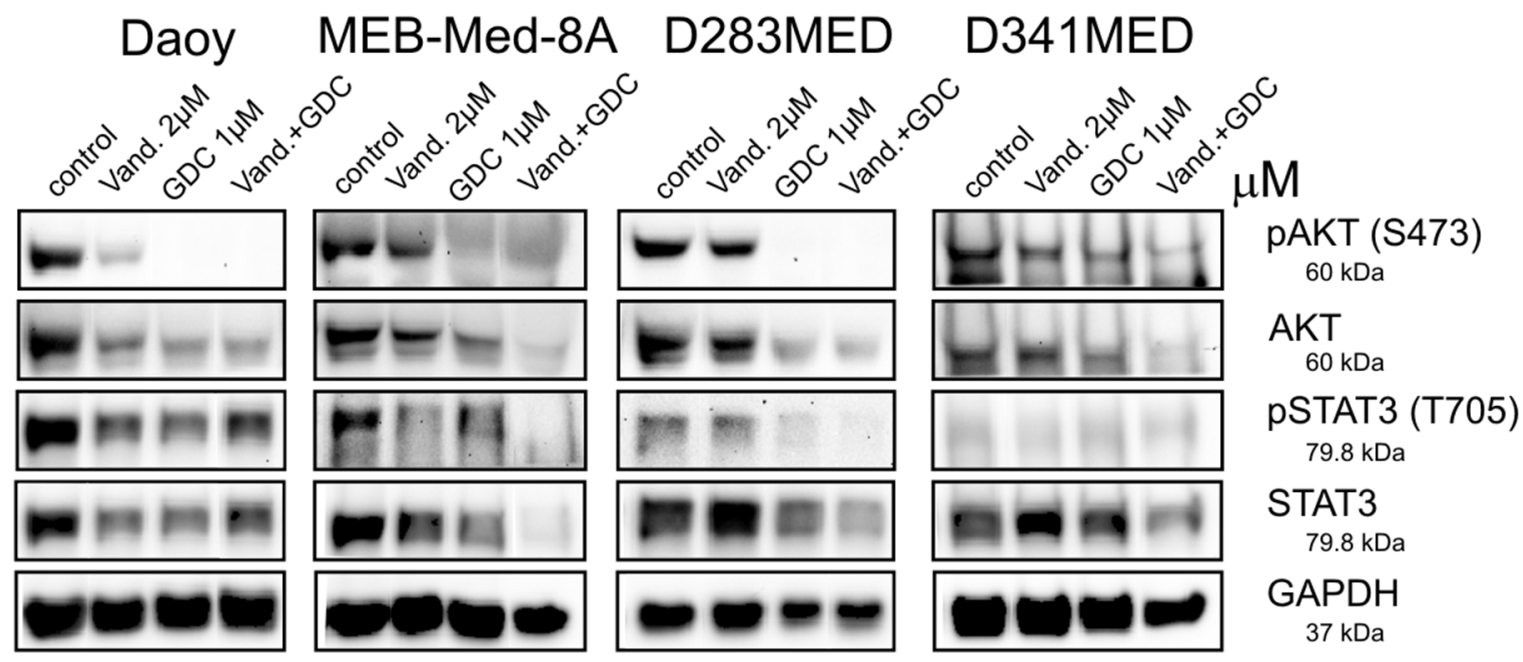

Figure 6: Combinational treatment of Vandetanib and GDC-0941 leads to profound inhibition of STAT3 and PI3K/ AKT activation. In Daoy, MEB-Med-8A, D283 Med and D341 Med cells were treated with $2 \mu \mathrm{M}$ of Vandetanib for 48h alone or in combination with $1 \mu \mathrm{M}$ of GDC-0941 respectively. Total protein levels and phosphorylation status of AKT and STAT3 were determined by Western blot. GAPDH served as loading control.
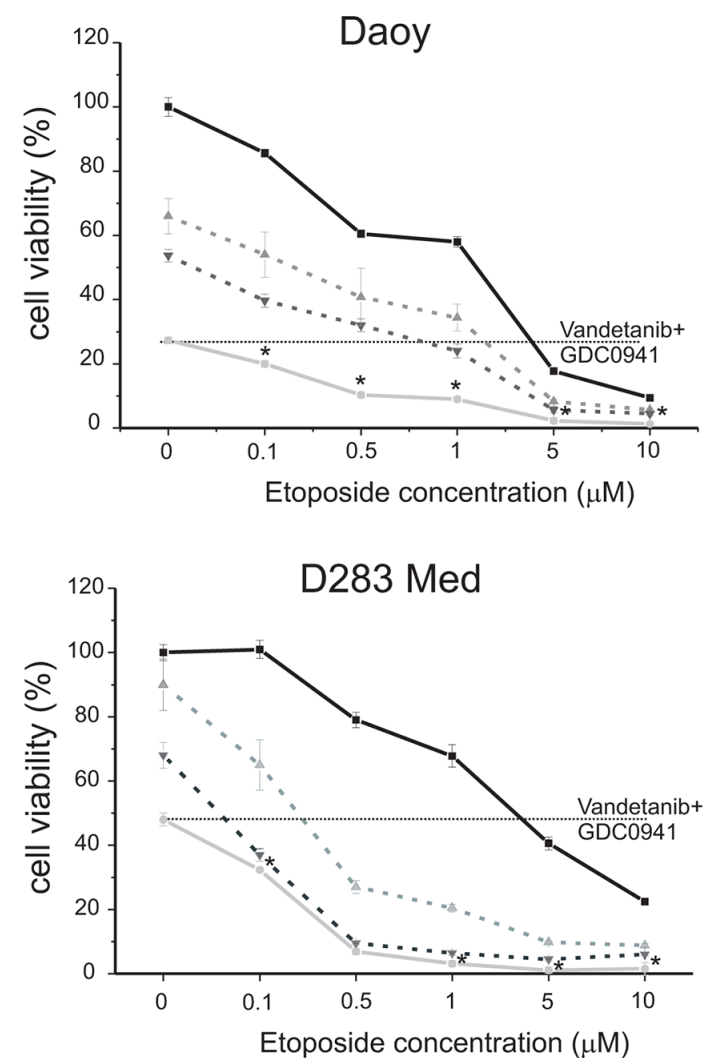
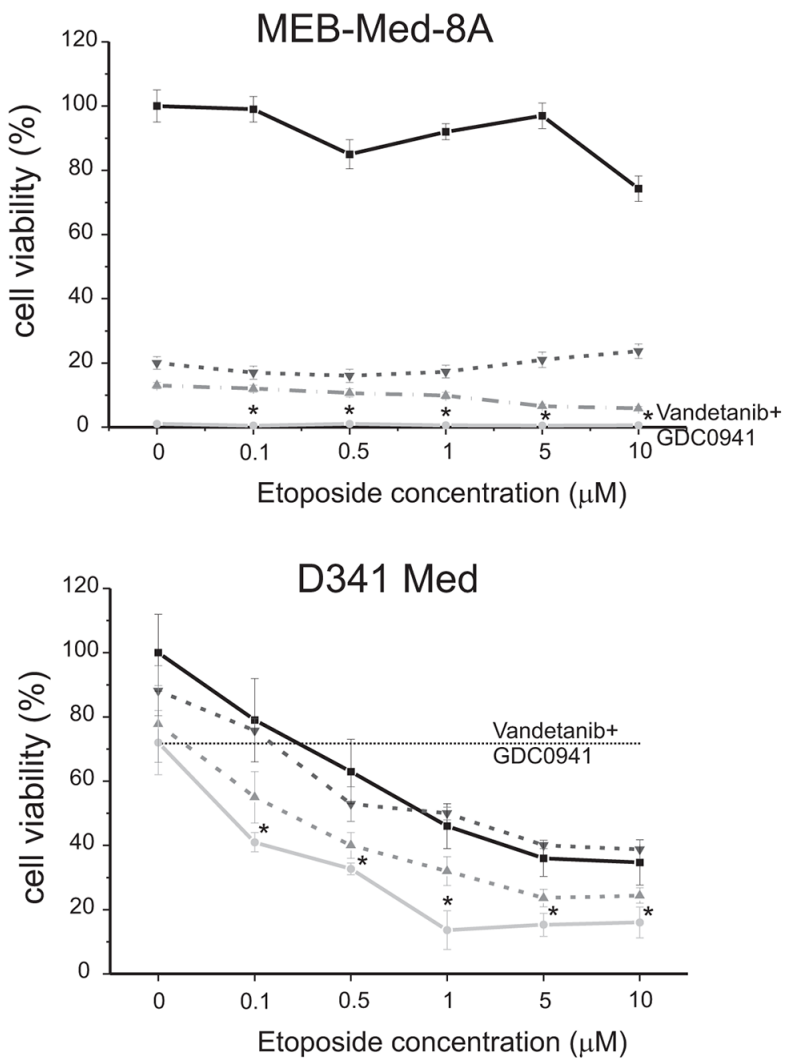

- E- Etoposide

$-\Delta$ - Vandetanib $2 \mu \mathrm{M}+$ Etoposide

$=\nabla$ - GDC0941 1 $\mu \mathrm{M}+$ Etoposide

- - Vandetani $2 \mu \mathrm{M}+\mathrm{GDC0941} 1 \mu \mathrm{M}+$ Etoposide

Figure 7: Concomittant application of Vandetanib, GDC-0941 and Etoposide displays additive cytotoxic activity. Daoy, MEB-Med-8A, D283 Med and D341 Med were treated with increasing concentrations of the standard chemotherapeutic Etoposide (0.1, $0.5,1,5,10 \mu \mathrm{M})$ in combination with $2 \mu \mathrm{M}$ of Vandetanib and $1 \mu \mathrm{M}$ of GDC-0941. 1-2 $\mu \mathrm{M}$ of Etoposide corresponds to cerebral spinal fluid levels, while $10 \mu \mathrm{M}$ of Etoposide corresponds to plasma levels. The vehicle DMSO served as control. After $48 \mathrm{~h}$ drug exposure cell viability was assessed by means of the MTS assay. Each experiment was performed in triplicates and repeated four times. 
We have previously show additive anti-neoplastic efficacy for the concomitant application of Etoposide and the PI3K-antagonist GDC-0941 in medulloblastoma cell lines [31]. Here we corroborate these results and document superior additive anti-neoplastic efficacy for the Vandetanib-Etoposide combination in comparison to single drug application. In the SHH-TP53-mutated cell line Daoy the anti-neoplastic efficacy of the VandetanibEtoposide and GDC-Etoposide combination were similar. In the MYC-amplified cell line D283 Med concomitant application of GDC-0941 and Etoposide displayed superior efficacy compared to concomitant application of Vandetanib and Etoposide. On the opposite in the MYC-amplified cell lines D341 Med and MEB-Med-8A we observed superior efficacy for the Vandetanib-Etoposide combination in comparison to the GDC-Etoposide combination. Of note, in MEB-Med-8A the anti-neoplastic efficacy was predominantly due to kinase inhibitor treatment.

With regards to concomitant application of Vandetanib and GDC-0941 in the SHH-TP53-mutated cell line Daoy we determined in our previous experiments a trend of higher anti-neoplastic efficacy in comparison to single drug application. Here in a cumulative assay determining anti-proliferative and cytotoxic drug effects by means of the metabolic state of the residual cell population this trend could be confirmed. Furthermore, we posed the question, whether inhibition of receptor tyrosine kinases and their downstream signaling molecules could enhance medulloblastoma standard treatment regimes. We treated the investigated cell lines therefore concomitantly with Vandetanib and GDC-0941 in the presence of the chemotherapeutic Etoposide. Indeed, in the SHH-TP53-mutated cell line Daoy as well as in the MYC-amplified cell lines D283 Med and D341 Med the application of the Vandetanib-GDC-Etoposide combination augmented the cytotoxic effect regardless of the applied concentration of Etoposide in comparison to single or dual drug application. In detail, in Daoy and D283 Med at 1 and $5 \mu \mathrm{M}$ of Etoposide respectively the concomitant application of Vandetanib, GDC-0941 and Etoposide resulted in complete loss of viable cells while in D341 Med at Etoposide concentrations of 1 and $5 \mu \mathrm{M}$ residual cell viability plateaued $13.6 \pm 6$ and $15.3 \pm 4 \%$ respectively. Applying higher Etoposide concentrations in combination with the applied kinase inhibitors did not lead to further enhancement of anti-neoplastic efficacy. In line with above described Etoposide resistancy of MEB-Med-8A concomitant application of Vandetanib and GDC-0941 was sufficient to reduce cell viability completely.

\section{DISCUSSION}

In this study we report that Vandetanib exerts anti-neoplastic activity against a panel of four pediatric medulloblastoma cell lines. MEB-Med-8A, D283 Med and D341 Med exhibit distinct characteristics such as
MYC-amplification and occurrence of isochromosome 17 of the most aggressive group of tumors within the NonWNT/Non-SHH group of medulloblastoma [19-23]. In contrast Daoy displays markers of a subentitiy of SHHgroup tumors that is characterized by mutation of tumor suppressor gene p53 (SHH-TP53-mutated) [24, 25]. A most recent report documents that patients suffering from SHH-TP53-mutated medulloblastoma also display extremely poor survival rates $[7,8]$.

Our analysis details that Vandetanib treatment at concentrations corresponding to patient plasma levels leads to marked loss of viable cells in MYC-amplified and SHH-TP53-mutated medulloblastoma cell lines. In line with the observed anti-tumorigenic efficacy of Vandetanib, transcriptional profiling revealed high mRNA levels of the Vandetanib target structures VEGFR 2 and 3 across all investigated cell lines. In contrast expression of EGFR was only present in Daoy (Supplementary Table 1). Dissecting the observed cumulative anti-neoplastic effect of Vandetanib reveals that the profound cytotoxic activity is complemented by a lower capacity to inhibit proliferation by arresting surviving medulloblastoma cells in $\mathrm{G}_{0} / \mathrm{G}_{1}$ Phase of the cell cycle (Supplementary Figure 1). The cytotoxic capacity of Vandetanib against medulloblastoma is also reflected in attenuated clonogenicity with profound reduction in colony number and size. Beyond cytotoxic and anti-proliferative effects we demonstrate that in vitro Vandetanib impairs migration of medulloblastoma cells, a prerequisite for invasion and metastasis. At this point it is noteworthy that inspite of the more narrow target-spectrum, the MKI Vandetanib displays similar in vitro efficacy against medulloblastoma as we have previously described for the broad-spectrum MKI Sorafenib and Pazopanib that inhibits amongst numerous other kinases also VEGFR 2 and 3 (Supplementary Table 2). In an orthotopic xenograft modell of MYC-amplified medulloblastoma, Sorafenib and Pazopanib suppressed tumor growth with significantly prolonged survival [28]. This finding is in line with clinical phase I/II trials that document tumor responses of the VEGF antibody bevacizumab in combination with standard chemotherapy in patients suffering from recurrent medulloblastoma [37]. The current investigation therefore corroborates pre-clinical and clinical reports delineating a key role for VEGF signaling in medulloblastoma development and progression that can be exploited for therapy. As it may be inferred that the documented cytotoxic in vitro effects for Vandetanib also translate into anti-neoplastic efficacy in vivo as shown for the broadspectrum MKI Sorafenib and Pazopanib, this approach warrants further evaluation [28].

In keeping with the anti-tumorigenic capacity of Vandetanib, we observed a moderate reduction in phosphorylation of the VEGFR 2/3 and EGFR downstream signaling molecule STAT3 in Daoy and MEB-Med-8A. These observations confirm previous investigations delineating the importance of STAT3 pathway activation 
downstream of aberrant receptor tyrosine kinases signaling for tumorigenesis in medulloblastoma [26-28]. In view of the pronounced cytotoxic activity of Vandetanib in D283 Med and D341 Med, lack of concomitant downregulation of STAT3 phosphorylation indicates that in these cell lines other pathways e.g. mitogen-activated protein kinase pathways as also shown for osteosarcoma might be involved in the integration of oncogenic signals transmitted by Vandetanib target structures [29, 38].

The narrow target profile of Vandetanib in comparison to broad-spectrum anti-angiogenetic MKI such as Pazopanib and Sorafenib results in better safety and tolerability (Supplementary Table 2) [39-42]. This is of particular interest since MKI-triggered side effects such as suppression of haematopoiesis are critical when considering administration of these drugs in combination with chemotherapy, immunotherapy and other targeted agents. At present only few combinations of broad-spectrum MKI with other targeted agents have been reported feasible in terms of safety [43-46]. Whether the more specific inhibitor Vandetanib shows less toxicity when combined with other targeted agents is momentarily under clinical investigation in a phase I trial testing the tolerability and efficacy of Vandetanib in combination with the PI3K/AKT pathway antagonist Everolismus (NCT01582191) in pediatric patients with advanced solid malignancies. Preliminary reports of this phase I study describe good tolerability of the drug combination and evidence of response in heavily pre-treated pediatric patients suffering from sarcoma [47]. Aberrant PI3K/AKT signaling downstream of receptor tyrosine kinases has also been shown critical for the development and progression of medulloblastoma [29, 30]. In this context we documented previously that the clinically available highly specific PI3K inhibitor GDC-0941 displays profound in vitro activity and prolonged the life of tumorbearing animals in an orthotopic xenograft mouse model of most aggressive MYC-amplified human medulloblastoma. [31]. Therefore, we assessed whether additional inhibition of the PI3K by GDC-0941 would further enhance the observed anti-neoplastic effect of Vandetanib. Indeed, here we document that Vandetanib in combination with GDC-0941 displays enhanced cytotoxicity against MYC-amplified and SHH-TP53-mutated tumor modeling cell lines compared to single drug application. In line with the enhanced antineoplastic effects of the Vandetanib-GDC-combination our findings demonstrate in MYC-amplified medulloblastoma a further reduction in AKT and STAT3 activity respectively in comparison to single drug application. This loss in activity was not solely due to inactivation of upstream kinases but also to reduction of the respective protein levels. Absence of AKT and STAT3 proteins would also counteract other oncogenic kinase signaling via these pathways. In context the SHH-TP53-mutated cell line Doay we did not detect a difference in AKT and STAT3 protein levels for the Vandetanib-GDC combination in comparison to single drug application. However, since only one SHH-TP53-mutated cell line was investigated and Vandetanib alone diminished besides STAT3 also AKT activity in the respective cell line, this result should be regarded with caution. With respect to the observed reduction in AKT activity might be of note that the SHH-TP53-mutated cell line expresses not only the Vandetanib target structures VEGFR 2 and 3 as the MYC-amplified cell lines but also EGFR. In breast cancer cell lines inhibition of VEGFR and PI3K signaling by the multi-kinase inhibitor Sorafenib leads to a reduction of MYC activity [48]. Whether Vandetanib or GDC-0941 also exert anti-neoplastic efficacy by suppressing MYC activity warrants further evaluation.

Given the recent publications on medulloblastoma subgrouping, the next step with regards to therapy is to adapt the existing treatment regimes for high risk medulloblastoma variants $[6,8,49]$. In this context our study documents besides anti-neoplastic efficacy of the standard chemotherapeutic Etoposide in MYC-amplified as well as SHH-TP53-mutated medulloblastoma cell lines an additive anti-tumorigenic efficacy for the EtoposideVandetanib combination in comparison to single drug application (Figure 7). Our previous publication documented also additive efficacy against the same panel of medulloblastoma cell lines for the concomitant application of Etoposide and the PI3K inhibitor GDC0941 [31]. Here we corroborate these results and show that the Vandetanib-Etoposide as well as the GDC-Etoposide combination display similar efficacy in SHH-TP53mutated and MYC-amplified cell lines.

Of note compared to single or dual drug application, concomitant application of all three drugs reduces residual cell viability to negligible levels even at very low doses of etoposide. This is of considerable interest since patients undergoing medulloblastoma therapy often suffer from neurological sequelae due to chemotherapeutic mediated long-term side-effects [50]. Therefore incorporation of targeted agents into standard treatment regimes could also positively affect the life-quality of patients significant reduction of applied chemotherapeutic dosage.

Of particular interest MEB-Med-8A, a cell line refractory to both etoposide as well as cisplatin (data not shown), was still highly sensitive to single treatment with Vandetanib and GDC-0941 respectively. Moreover, concomitant application of Vandetanib and GDC-0941 resulted in de facto complete loss of cell viability. Whether this finding, although promising, can be translated to refractory tumors therapy in patients needs further evaluation.

The development of rational and personalized cancer therapy depends on the identification of valid biomarkers. Expression of target structures might serve as markers for the integration of TKI such as Vandetanib into standard treatment regimes of medulloblastoma. However, in other cancers microRNA expression patters are discussed as promising indicators of eligibility for patient treatment with Vandetanib [51]. 
In general, our findings underscore the notion that combined inhibition of specific oncogenic tyrosine kinases together with important downstream signaling nodes - such as the PI3K that integrates signals of multiple oncogenic kinases - can enhance anti-neoplastic efficacy in combination with standard medulloblastoma chemotherapeutics.

In conclusion, our study demonstrates that Vandetanib, a clinically available angiogenesis inhibitor, displays direct anti-neoplastic activity against pediatric medulloblastoma cell lines modeling the clinically most aggressive $\mathrm{SHH}-$ TP53-mutated and MYC-amplified tumor variants. Furthermore, our study documents that combined application of Vandetanib and GDC-0941, a clinically available PI3K/ AKT pathway inhibitor, results in fortified anti-neoplastic responses against SHH-TP53-mutated and MYC-amplified medulloblastoma. Furthermore, we delineate that Vandetanib in combination with the standard chemotherapeutic Etoposid displays additive anti-neoplastic efficacy that can be further enhanced by PI3K inhibition. Therefore, our findings provide a rational to further investigate Vandetanib alone, in combination with PI3K/AKT pathway inhibitors and standard chemotherapeutics for the treatment of medulloblastoma variants that despite of intensive multi-modality treatment are currently still associated with poor prognosis.

\section{MATERIALS AND METHODS}

\section{Reagents and antibodies}

Vandetanib and GDC-0941 were obtained from LC Laboratories. The primary antibody pSTAT3 (TYR705, D3A7), STAT3 (124H6), pAKT (Ser473), AKT (11E7) and GAPDH (D18H11) were purchased from Cell Signaling while secondary antibodies were purchased from Dianova. Carboxyfluoreszein-Succinimidyl Ester (CFSE) was purchased from Invitrogen, while Hoechst 33258 was provided by Sigma.

\section{Cell culture}

The human medulloblastoma cell lines, Daoy (HTB 186), D283 Med (HTB-185) and D341 Med (HTB-187) were obtained from American Type Culture Collection (ATCC). The medulloblastoma cell line, MEB-Med-8A, was generated by Prof. T. Pietsch. The medulloblastoma cell lines Daoy, D283 Med and MEB-Med-8A were maintained in complete medium, namely Dulbecco's Modified Eagle Medium (DMEM, PAA) with L-glutamine supplemented with $1 \mathrm{mM}$ sodium pyruvate (PAA), 1\% penicilline/streptomycine (Invitrogen) and 10\% fetal bovine serum (FBS, Invitrogen). The medulloblastoma cell line D341 Med was maintained in DMEM with L-glutamine supplemented with $1 \mathrm{mM}$ sodium pyruvate, $1 \%$ penicilline/streptomycine and $10 \%$ Human Serum (HS, PAA).

\section{Cell viability assay}

Cell viability was assessed with CellTiter 96 Aqueous One Solution Cell proliferation Assay (Promega) that contains 3-(4,5-dimethylthiazol-2-yl)-5-(3- carboxymethoxyphenyl)2-(4-sulfophenyl)-2H-tetrazolium (MTS). To ensure a linear growth curve over $48 \mathrm{~h}$ for assessment of MKI-effects, each well of 96-well plates was seeded with $2.5 \times 10^{3}$ Daoy, $6 \times 10^{3}$ MEB-Med-8A, $10^{4}$ D283 Med and 104 D341 Med cells respectively. After overnight culture in complete medium, the cells were treated with $1,2,4$ and $10 \mu \mathrm{M}$ of Vandetanib alone or in combination with $0.1,0.5,1,5$ and $10 \mu \mathrm{M}$ of etoposide and $1 \mu \mathrm{M}$ of GDC-0941. The vehicle Dimethylsulfoxid (DMSO) served as control. After $48 \mathrm{~h}$ of MKI treatment, MTS was added according to the supplier's protocol and the absorbance was measured at $490 \mathrm{~nm}$ using an ELISA plate reader (Victor ${ }^{2}$ Wallac, Perkin Elmer). Cell viability was calculated in percent of control.

\section{Combined proliferation and cell death assay}

Medulloblastoma cells were stained with CFSE according to the instructions of the supplier. Daoy, MEBMed-8A, D283 Med and D341 Med cells were seeded in 6-well cell culture dishes in complete medium. After overnight culture, the cells were treated with $2 \mu \mathrm{M}$ of Vandetanib for $48 \mathrm{~h}$. Thereafter floating and attached cells were collected, resuspended in $200 \mu \mathrm{l}$, stained with Hoechst33258 and analysed by flow cytometry. The number of viable cells was assessed for $120 \mathrm{sec}$ in same volume and at constant speed. Proliferation was traced by CFSE staining and normalized to the control DMSO, while cell death was determined by Hoechst33258 staining.

\section{Cell migration assay}

The in vitro scratch assay was performed as described by Liang et al. [52]. Briefly, Daoy cells were plated in 12-well cell culture dishes. The cells were allowed to adhere and spread for $12 \mathrm{~h}$ at $37{ }^{\circ} \mathrm{C}$. The confluent monolayer was scratched in a straight line with a p200 pipette tip. The debris was removed and the cells were then incubated with Vandetanib. The vehicle DMSO served as control. After $24 \mathrm{~h}$ of treatment, migration of cells into the "wound" was photographed at 10x magnification (Nikon Eclipse TiS inverted microscope attached to a CCD monochrome camera DS 2M). The distance of migration was analyzed by means of NISElements Imaging Software.

\section{Immunoblotting analysis}

A total protein concentration of $25 \mu \mathrm{g}$ derived from medulloblastoma cell lines was separated by SDSpolyacrylamide gel electrophoresis and transferred to nitrocellulose membranes (Bio-Rad). The membranes were blocked for $1 \mathrm{~h}$ at RT in $1 \mathrm{x}$ Tris-buffered saline 
containing $0.1 \%$ tween-20 (TBST) supplemented with $5 \%$ BSA. Thereafter, the membranes were incubated with the primary antibodies overnight at $4^{\circ} \mathrm{C}$ and subsequently with the respective secondary antibody for $1 \mathrm{~h}$ at room temperature. Immunoreactivity was detected by chemiluminescence and quantified by means of a ChemiDoc XRS Imaging System (Bio-Rad).

\section{Colony formation assay}

The cell lines Daoy (200 cells/well) and MEBMed-8A (1000 cells/well) were plated in six well cell culture dishes. The cells were allowed to adhere and spread properly for $12 \mathrm{~h}$ at $37^{\circ} \mathrm{C}$. Thereafter the cells were exposed to 1, 2 and $4 \mu \mathrm{M}$ of Vandetanib. After $48 \mathrm{~h}$ of exposure the cells were washed with standard medium to remove any trace of the inhibitor and cultured for another week. Colony numbers, and colony size was assessed by IMAGEJ. Particles smaller than 40 pixel $^{2}$ were excluded from the analysis since these represented stain artefacts, cell detritus or non-proliferating single cells.

\section{Statistical analysis}

The two-sided Student's $t$-test was applied to determine statistical significance between groups. $\mathrm{p}<0.05$ (*), was considered as statistically significant. Values stated within text and figures represent mean \pm standard deviation.

\section{Abbreviations}

ATCC: American Type Culture Collection; CFSE: carboxyfluoreszein-succinimidyl ester; DMEM: Dulbecco's modified eagle medium; DMSO: dimethylsulfoxid; EGFR: epidermal growth factor receptor; M: molar; MKI: multikinase Inhibitor; MTS: 3-(4,5-dimethylthiazol-2-yl)-5-(3carboxy-methoxyphenyl)-2-(4-sulfophenyl)-2H-tetrayolium; PI3K: phosphoinositide-3-kinase; STAT3: signal transducer and activator of transcription 3; VEGFR: vascular endothelial growth factor receptor.

\section{ACKNOWLEDGMENTS}

We gratefully acknowledge the expert technical support of Anne Petruschke

\section{CONFLICTS OF INTEREST}

The authors declare that they have no conflict of interest.

\section{REFERENCES}

1. Kim WY, Lee HY. Brain angiogenesis in developmental and pathological processes: mechanism and therapeutic intervention in brain tumors. FEBS J. 2009; 276:4653-4664.
2. Trevisan E, Bertero L, Bosa C, Magistrello M, Pellerino A, Ruda R, Soffietti R. Antiangiogenic therapy of brain tumors: the role of bevacizumab. Neurol Sci. 2014; 35:507-514.

3. Fields EC, Damek D, Gaspar LE, Liu AK, Kavanagh BD, Waziri A, Lillehei K, Chen C. Phase I dose escalation trial of vandetanib with fractionated radiosurgery in patients with recurrent malignant gliomas. Int J Radiat Oncol Biol Phys. 2012; 82:51-57.

4. Drappatz J, Norden AD, Wong ET, Doherty LM, Lafrankie DC, Ciampa A, Kesari S, Sceppa C, Gerard M, Phan P, Schiff D, Batchelor TT, Ligon KL, et al. Phase I study of vandetanib with radiotherapy and temozolomide for newly diagnosed glioblastoma. Int J Radiat Oncol Biol Phys. 2010; 78:85-90.

5. Broniscer A, Baker SD, Wetmore C, Pai Panandiker AS, Huang J, Davidoff AM, Onar-Thomas A, Panetta JC, Chin TK, Merchant TE, Baker JN, Kaste SC, Gajjar A, Stewart $\mathrm{CF}$. Phase I trial, pharmacokinetics, and pharmacodynamics of vandetanib and dasatinib in children with newly diagnosed diffuse intrinsic pontine glioma. Clin Cancer Res. 2013; 19:3050-3058.

6. Northcott PA, Dubuc AM, Pfister S, Taylor MD. Molecular subgroups of medulloblastoma. Expert Rev Neurother. $2012 ; 12: 871-884$.

7. Ramaswamy V, Remke M, Bouffet E, Faria CC, Perreault S, Cho YJ, Shih DJ, Luu B, Dubuc AM, Northcott PA, Schuller U, Gururangan S, McLendon R, et al. Recurrence patterns across medulloblastoma subgroups: an integrated clinical and molecular analysis. Lancet Oncol. 2013; 14:1200-1207.

8. Zhukova N, Ramaswamy V, Remke M, Pfaff E, Shih DJ, Martin DC, Castelo-Branco P, Baskin B, Ray PN, Bouffet E, von Bueren AO, Jones DT, Northcott PA, et al. Subgroupspecific prognostic implications of TP53 mutation in medulloblastoma. J Clin Oncol. 2013; 31:2927-2935.

9. Brave SR, Odedra R, James NH, Smith NR, Marshall GB, Acheson KL, Baker D, Howard Z, Jackson L, Ratcliffe K, Wainwright A, Lovick SC, Hickinson DM, et al. Vandetanib inhibits both VEGFR-2 and EGFR signalling at clinically relevant drug levels in preclinical models of human cancer. Int J Oncol. 2011; 39:271-278.

10. Klein JD, Christopoulos A, Ahn SM, Gooding WE, Grandis JR, Kim S. Antitumor effect of vandetanib through EGFR inhibition in head and neck squamous cell carcinoma. Head Neck. 2012; 34:1269-1276.

11. Siegfried JM, Gubish CT, Rothstein ME, Henry C, Stabile LP. Combining the multitargeted tyrosine kinase inhibitor vandetanib with the antiestrogen fulvestrant enhances its antitumor effect in non-small cell lung cancer. J Thorac Oncol. 2012; 7:485-495.

12. Meco D, Servidei T, Riccardi A, Ferlini C, Cusano G, Zannoni GF, Giangaspero F, Riccardi R. Antitumor effect in medulloblastoma cells by gefitinib: ectopic HER2 overexpression enhances gefitinib effects in vivo. Neuro Oncol. 2009; 11:250-259. 
13. Slongo ML, Molena B, Brunati AM, Frasson M, Gardiman M, Carli M, Perilongo G, Rosolen A, Onisto M. Functional VEGF and VEGF receptors are expressed in human medulloblastomas. Neuro Oncol. 2007; 9:384-392.

14. Reifenberger G, Prior R, Deckert M, Wechsler W. Epidermal growth factor receptor expression and growth fraction in human tumours of the nervous system. Virchows Arch A Pathol Anat Histopathol. 1989; 414:147-155.

15. Meco D, Servidei T, Zannoni GF, Martinelli E, Prisco MG, de Waure C, Riccardi R. Dual inhibitor AEE788 reduces tumor growth in preclinical models of medulloblastoma. Transl Oncol. 2010; 3:326-335.

16. Liu W, Zhang S, Zhang L, Cui Q, Wang J, Gui T, Pang Q. A prognostic analysis of pediatrics central nervous system small cell tumors: evaluation of EGFR family gene amplification and overexpression. Diagn Pathol. 2014; 9:132.

17. Chau NG, Haddad RI. Vandetanib for the treatment of medullary thyroid cancer. Clin Cancer Res. 2013; 19:524-529.

18. Lodish M, Gkourogianni A, Bornstein E, Sinaii N, Fox E, Chuk M, Marcus L, Akshintala S, Balis F, Widemann B, Stratakis CA. Patterns of thyroid hormone levels in pediatric medullary thyroid carcinoma patients on vandetanib therapy. Int J Pediatr Endocrinol. 2015; 2015:3.

19. Yokota N, Mainprize TG, Taylor MD, Kohata T, Loreto M, Ueda S, Dura W, Grajkowska W, Kuo JS, Rutka JT. Identification of differentially expressed and developmentally regulated genes in medulloblastoma using suppression subtraction hybridization. Oncogene. 2004; 23:3444-3453.

20. Bodey BS, Siegel SE, Kaiser HE. (2004). Molecular Markers of Brain Tumor Cells: Kluwer Academic Publisher.

21. Rosen ST. (2002). Clinically relevant resistance in cancer chemotherapy: Kluwer Academic Publishers.

22. Friedman HS, Burger PC, Bigner SH, Trojanowski JQ, Brodeur GM, He XM, Wikstrand CJ, Kurtzberg J, Berens ME, Halperin EC, Bigner DD. Phenotypic and genotypic analysis of a human medulloblastoma cell line and transplantable xenograft (D341 Med) demonstrating amplification of c-myc. Am J Pathol. 1988; 130:472-484.

23. Calabrese CM, Gaber WM, Kilmar J, Fuller C, Allen M, Gilbertson RJ. (2005). Autofluorescent mouse models of human medulloblastoma. AACR Meeting. (Anaheim, California: Proc Amer Assoc Cancer Res), pp. 903-c-904.

24. Jacobsen PF, Jenkyn DJ, Papadimitriou JM. Establishment of a human medulloblastoma cell line and its heterotransplantation into nude mice. J Neuropathol Exp Neurol. 1985; 44:472-485.

25. Briggs KJ, Corcoran-Schwartz IM, Zhang W, Harcke T, Devereux WL, Baylin SB, Eberhart CG, Watkins DN. Cooperation between the Hic1 and Ptch1 tumor suppressors in medulloblastoma. Genes Dev. 2008; 22:770-785.
26. Yang F, Van Meter TE, Buettner R, Hedvat M, Liang W, Kowolik CM, Mepani N, Mirosevich J, Nam S, Chen MY, Tye G, Kirschbaum M, Jove R. Sorafenib inhibits signal transducer and activator of transcription 3 signaling associated with growth arrest and apoptosis of medulloblastomas. Mol Cancer Ther. 2008; 7:3519-3526.

27. Yang F, Jove V, Xin H, Hedvat M, Van Meter TE, Yu H. Sunitinib induces apoptosis and growth arrest of medulloblastoma tumor cells by inhibiting STAT3 and AKT signaling pathways. Mol Cancer Res. 2010; 8:35-45.

28. Craveiro RB, Ehrhardt M, Holst MI, Pietsch T, Dilloo D. In comparative analysis of multi-kinase inhibitors for targeted medulloblastoma therapy pazopanib exhibits promising in vitro and in vivo efficacy. Oncotarget. 2014; 5:7149-7161. doi: 10.18632/oncotarget.2240.

29. Wlodarski P, Grajkowska W, Lojek M, Rainko K, Jozwiak J. Activation of Akt and Erk pathways in medulloblastoma. Folia Neuropathol. 2006; 44:214-220.

30. Dimitrova V, Arcaro A. Targeting the PI3K/AKT/mTOR signaling pathway in medulloblastoma. Curr Mol Med. $2015 ; 15: 82-93$.

31. Ehrhardt M, Craveiro RB, Holst MI, Pietsch T, Dilloo D. The PI3K inhibitor GDC-0941 displays promising in vitro and in vivo efficacy for targeted medulloblastoma therapy. Oncotarget. 2015; 6:802-813. doi: 10.18632/oncotarget.2742.

32. de Boer R, Humblet Y, Wolf J, Nogova L, Ruffert K, Milenkova T, Smith R, Godwood A, Vansteenkiste J. An open-label study of vandetanib with pemetrexed in patients with previously treated non-small-cell lung cancer. Ann Oncol. 2009; 20:486-491.

33. Abouantoun TJ, MacDonald TJ. Imatinib blocks migration and invasion of medulloblastoma cells by concurrently inhibiting activation of platelet-derived growth factor receptor and transactivation of epidermal growth factor receptor. Mol Cancer Ther. 2009; 8:1137-1147.

34. Moreno Garcia V, Baird RD, Shah KJ, Basu B, Tunariu N, Blanco M, Cassier PA, Pedersen JV, Puglisi M, Sarker D, Papadatos-Pastos D, Omlin AG, Biondo A, et al. A phase I study evaluating GDC-0941, an oral phosphoinositide-3 kinase (PI3K) inhibitor, in patients with advanced solid tumors or multiple myeloma. J Clin Oncol 29: 2011: 3021.

35. Kiya K, Uozumi T, Ogasawara H, Sugiyama K, Hotta T, Mikami T, Kurisu K. Penetration of etoposide into human malignant brain tumors after intravenous and oral administration. Cancer Chemother Pharmacol. 1992; 29:339-342.

36. Hande KR, Wedlund PJ, Noone RM, Wilkinson GR, Greco FA, Wolff SN. Pharmacokinetics of high-dose etoposide (VP-16-213) administered to cancer patients. Cancer Res. $1984 ; 44: 379-382$.

37. Aguilera D, Mazewski C, Fangusaro J, MacDonald TJ, McNall-Knapp RY, Hayes LL, Kim S, Castellino RC. Response to bevacizumab, irinotecan, and 
temozolomide in children with relapsed medulloblastoma: a multi-institutional experience. Childs Nerv Syst. 2013; 29:589-596

38. Liu J, Wu J, Zhou L, Pan C, Zhou Y, Du W, Chen JM, Zhu X, Shen J, Chen S, Liu RY, Huang W. ZD6474, a new treatment strategy for human osteosarcoma, and its potential synergistic effect with celecoxib. Oncotarget. 2015; 6:21341-21352. doi: 10.18632/oncotarget.4179.

39. Oh WK, McDermott D, Porta C, Levy A, Elaidi R, Scotte F, Hawkins R, Castellano D, Bellmunt J, Rha SY, Sun JM, Nathan P, Feinberg BA, et al. Angiogenesis inhibitor therapies for advanced renal cell carcinoma: toxicity and treatment patterns in clinical practice from a global medical chart review. Int J Oncol. 2014; 44:5-16.

40. Grande E, Kreissl MC, Filetti S, Newbold K, Reinisch W, Robert C, Schlumberger M, Tolstrup LK, Zamorano JL, Capdevila J. Vandetanib in advanced medullary thyroid cancer: review of adverse event management strategies. Adv Ther. 2013; 30:945-966.

41. Eskens FA, Verweij J. The clinical toxicity profile of vascular endothelial growth factor (VEGF) and vascular endothelial growth factor receptor (VEGFR) targeting angiogenesis inhibitors; a review. Eur J Cancer. 2006; 42:3127-3139.

42. Fallahi P, Di Bari F, Ferrari SM, Spisni R, Materazzi G, Miccoli P, Benvenga S, Antonelli A. Selective use of vandetanib in the treatment of thyroid cancer. Drug Des Dev Ther. 2015; 9:3459-3470.

43. Mahalingam D, Malik L, Beeram M, Rodon J, Sankhala K, Mita A, Benjamin D, Ketchum N, Michalek J, Tolcher A, Wright J, Sarantopoulos J. Phase II study evaluating the efficacy, safety, and pharmacodynamic correlative study of dual antiangiogenic inhibition using bevacizumab in combination with sorafenib in patients with advanced malignant melanoma. Cancer Chemother Pharmacol. 2014; 74:77-84.

44. Gangadhar TC, Cohen EE, Wu K, Janisch L, Geary D, Kocherginsky M, House LK, Ramirez J, Undevia SD, Maitland ML, Fleming GF, Ratain MJ. Two drug interaction studies of sirolimus in combination with sorafenib or sunitinib in patients with advanced malignancies. Clin Cancer Res. 2011; 17:1956-1963.
45. Gomez-Martin C, Bustamante J, Castroagudin JF, Salcedo M, Garralda E, Testillano M, Herrero I, Matilla A, Sangro B. Efficacy and safety of sorafenib in combination with mammalian target of rapamycin inhibitors for recurrent hepatocellular carcinoma after liver transplantation. Liver Transpl. 2012; 18:45-52.

46. Gross-Goupil M, Francois L, Quivy A, Ravaud A. Axitinib: a review of its safety and efficacy in the treatment of adults with advanced renal cell carcinoma. Clin Med Insights Oncol. 2013; 7:269-277.

47. Moonat HR, Roxas M, Huh WW, Herzog CE, Piha-Paul S, Daw NC, Rytting M, Mote E, Ward EN, Amin Y, MericBernstam F, Schwartz CL, Subbiah V. Phase I study of Everolimus (mTOR inhibitor) in combination with Vandetanib (multikinase inhibitor of EGFR, VEGFR, RET) in children, adolescents, and young adults with advanced solid tumors. Cancer Res. 2016; 76:A48.

48. Booth L, Roberts JL, Tavallai M, Chuckalovcak J, Stringer DK, Koromilas AE, Boone DL, McGuire WP, Poklepovic A, Dent P. [Pemetrexed + Sorafenib] lethality is increased by inhibition of ERBB1/2/3-PI3K-NFאB compensatory survival signaling. Oncotarget. 2016; 7:23608-23632. doi: 10.18632/oncotarget.8281.

49. Kool M, Korshunov A, Remke M, Jones DT, Schlanstein M, Northcott PA, Cho YJ, Koster J, Schouten-van Meeteren A, van Vuurden D, Clifford SC, Pietsch $\mathrm{T}$, von Bueren $\mathrm{AO}$, et al. Molecular subgroups of medulloblastoma: an international meta-analysis of transcriptome, genetic aberrations, and clinical data of WNT, SHH, Group 3, and Group 4 medulloblastomas. Acta Neuropathol. 2012; 123:473-484.

50. Monje M, Fisher PG, Paul Graham Fisher, MD. Neurological complications following treatment of children with brain tumors. J Pediatr Rehabil Med. 2011; 4:31-36.

51. Lassalle S, Zangari J, Popa A, Ilie M, Hofman V, Long E, Patey M, Tissier F, Belléannée G, Trouette H, Catargi B, Peyrottes I, Sadoul JL, et al. MicroRNA-375/SEC23A as biomarkers of the in vitro efficacy of vandetanib. Oncotarget. 2016; 7:30461-30478. doi: 10.18632/oncotarget.8458.

52. Liang CC, Park AY, Guan JL. In vitro scratch assay: a convenient and inexpensive method for analysis of cell migration in vitro. Nat Protoc. 2007; 2:329-333. 